\title{
A influência do contexto político-econômico na propaganda impressa brasileira dos anos 50 aos anos 90: um olhar semiótico
}

\author{
Bárbara Fernandes Raposo Vieira' \\ Úrsula Betina Diesel ${ }^{2}$
}

\section{Resumo}

Este estudo tem como finalidade identificar a influência do contexto político-econômico nas propagandas impressas brasileiras dos anos 50 aos anos 90 . Para isso foram feitas análises de três ou quatro anúncios de cada década pertencentes a segmentos diferentes de mercado. Relata-se um histórico sincrônico da propaganda e da história brasileira a partir dos anos 50 até o final do século XX, expondo os principais acontecimentos da política, economia e propaganda. Apresenta-se, em uma próxima etapa, a metodologia em que as análises foram baseadas, como a semiótica via o "modelo" de Martine Joly. Espera-se que este estudo revele a importância do contexto político-econômico na propaganda brasileira.

Palavras-chave: Propaganda - Brasil. História - Brasil. Semiótica.

\section{Introdução}

Não tem como pensar em propaganda, política, economia e sociedade separadamente. A relação entre esses contextos é tão íntima que eles são vistos como um "todo", uma relação de interdependência, seja ela direta ou indireta. Ao analisarmos a história de um país juntamente com sua propaganda, podem ser vistas linhas paralelas que seguem simultaneamente. Até que ponto o contexto político-econômico de um país pode influenciar sua propaganda?

1 Graduada em Comunicação Social com ênfase em Publicidade e Propaganda; <barbara. frv@gmail.com>

2 Mestre em Comunicação Social, com enfoque em Semiótica. Professora no Curso de Comunicação Social do UniCEUB; <ursuladiesel@gmail.com> 
Este estudo tem a proposta de analisar a influência do contexto político-econômico nos anúncios impressos da propaganda brasileira que permeiam as décadas de 50, 60, 70, 80 e 90; e, então detectar a que ponto essa influência pode chegar. Essas décadas abrangem um grande período de tempo, porém contemplam, também, as décadas em que o Brasil se transformou e amadureceu. Foram escolhidos anúncios de segmentos diferentes do mercado para mostrar se essa influência se dá de forma uniforme ou atinge somente um ou outro setor do mercado de consumo.

Para saber a real influência do contexto histórico na propaganda, é exposto o relato sincrônico da propaganda e da história brasileira, a partir dos anos 50 até o final do século XX. Esse panorama mune o projeto para a análise semiótica dos anúncios que teve como base os conceitos de Charles Peirce e o modelo de análise de publicidade empregado por Martine Joly, baseando-se em uma análise semiótica da imagem publicitária.

\section{Um relato sincrônico da história e da propaganda brasileira: dos anos $\mathbf{5 0}$ ao final do século $X X$}

Os 40 anos, descritos de forma breve a seguir, marcam uma época de amadurecimento do Brasil. Um país que passou por um duro regime militar, mas retornou à democracia com equilíbrio e seriedade; passou de um país essencialmente agrícola para urbano; teve crescimento na indústria de bens e capital, elevando o consumo e fazendo até surgir uma nova classe social, que sofreu com altas extraordinárias na inflação e que, por muitas vezes, levou o brasileiro a se orgulhar da sua nacionalidade. Essas décadas também marcam a profissionalização e crescimento qualitativo na propaganda brasileira. Todo esse cenário era campo fértil para a propaganda no país.

Os anos 50 começam sob forte otimismo. O tema que tomava conta do Brasil era o desenvolvimento do país - tanto social e econômico, quanto cultural. Essa década traz consigo o início da moderna propaganda brasileira. A crescente industrialização e urbanização proporcionam um mercado promissor para a propaganda brasileira. A propaganda, na década de 50, reflete as duas faces da socie- 
dade brasileira: por um lado, o país era essencialmente agrícola, com a maioria da população morando no campo; e por outro lado, imigrantes europeus trazem suas influências e costumes, causando efervescência na sociedade (GRACIOSO; PENTEADO, 2008). Em 1950, surge o meio que vai transformar a comunicação no Brasil. A TV nasce e revoluciona a cultura, o comportamento, a economia e, consequentemente, a publicidade brasileira.

Com a posse de Juscelino Kubitschek (1956), dá-se início a era desenvolvimentista e nacionalista, quando chegam as empresas às cidades, ao lar e ao comportamento da população sem pedir licença. Agora a palavra era "industrialização" a qualquer preço. O Brasil cresce econômica e populacionalmente. A industrialização gera modernização. Modernizam-se os hábitos, pensamentos, modo de vida, e a população vai se tornando um pouco mais urbana (RODRIGUES, 2002).

A década de 60 é de transformações radicais para a propaganda brasileira. O Brasil avança nas mudanças em velocidade vertiginosa, ao mesmo tempo em que a década é caracterizada pela repressão política, sequestro das liberdades políticas, do direito de ir e vir, ocasionando rebeldia e contestação.

Em 1964, o Brasil ingressa no Regime Militar, que viria durar 21 anos. O golpe depõe João Goulart, sem qualquer possibilidade de reação, e institui uma ditadura militar. Os setores da sociedade que participaram do movimento militar em 1964 tinham expectativas em comum: repressão aos movimentos das classes dominadas, o fim da proliferação do socialismo e a reorientação da economia. A propaganda adere conceitos como ufanismo nacionalista, ideologia progressista e busca pela criação de um sentimento pátrio profundo (MARCONDES, 2002). A TV tem grande importância no movimento militar.

Enquanto isso, o Brasil também vive um clima de progresso. É inaugurada a cidade de Brasília, a nova capital do Brasil. "A inauguração de Brasília fez os brasileiros crerem que a alvorada de um futuro promissor havia chegado”. (GRACIOSO; PENTEADO, 2008, p. 115). Com todo esse impulso, surge a primeira classe média moderna do Brasil, que se concentrava nos grandes centros com potencial de ter casa, automóveis próprios e itens como geladeira, aspirador de pó e televisor. 
De meados da década de 60 à década de 70, a propaganda brasileira passa por grande crescimento e profissionalização. Ela começa a ser respeitada e admirada no mundo, dando um "grande salto qualitativo" (GRACIOSO; PENTEADO, 2008, p. 134). Essa guinada da propaganda brasileira se deu graças ao "milagre econômico", que fez com que os padrões de qualidade, de produtos e serviços, fossem revistos e mais exigidos. Esse conjunto de medidas econômicas incentivou também o reaquecimento da economia, fazendo-a crescer de forma excepcional.

O governo do General Médice (1969-1974), faz o uso massivo dos meios de comunicação com o objetivo de estabelecer uma visão positiva sobre o Governo Militar. O governo contrata agências de propaganda, que criam slogans como: "Pra frente Brasil", "Ninguém segura este país" e "Brasil, ame-o ou deixe-o". Esses slogans não eram só slogans, eram palavras de ordem e faziam parte do discurso político da época. Os meios de comunicação foram censurados e sofreram repressão intensa.

A relação entre propaganda e os militares foi íntima, nesta época. O governo investiu substancialmente em publicidade para consolidar sua obra e difundir seus valores. Transformou-se então no maior anunciante do país (MARCONDES, 2002, p. 45).

Na transição entre as décadas de 70 e 80, a propaganda brasileira recebe influências que agiam no mundo todo. Enquanto nos países de primeiro mundo a sociedade apresentava características permissivas, os comerciais tornavam-se mais ousados e falavam de sexo. Já no Brasil era impossível seguir esses modelos por causa da censura imposta pelo regime militar,a todas as formas de comunicação. Nessa época, a propaganda brasileira vive, o que os autores chamam de a "fase de ouro", e foi considerada uma das três mais criativas do mundo (MARCONDES, 2002).

Inicia-se uma abertura política que se deu de forma lenta e gradual. O processo de abertura política é marcado pelo retorno dos exilados políticos em 1979, fato que põe fim às especulações de uma continuidade prolongada do regime militar.

Os anos 80 são marcados por dois sentimentos opostos: euforia e agitação intensa; dificuldades e incertezas para a história e a propaganda brasileira. A década 
ficou conhecida como a "década perdida". O país passa por grandes dificuldades econômicas ocasionadas, principalmente, pelo elevado grau de endividamento externo.

Os trancos da economia vão se refletir na propaganda de maneira inequívoca [...]. Nos períodos de alta inflacionária, os anunciantes recuavam e as verbas publicitárias praticamente desapareciam. Nos períodos de alguma retomada do consumo, os anunciantes apenas mantinham seus investimentos de sustentação publicitária, já que para o mercado não era indispensável fazer propaganda (MARCONDES, 2002 p. 52).

As agências ganham prêmios por suas criações. "A partir dos anos 80, com crise ou sem ela, o Brasil nunca mais deixaria de ser reconhecido como um dos países mais criativos da propaganda mundial" (MARCONDES, 2002, p. 54) Muitos prêmios no Festival de Cannes, Colunistas, entre outros. Alguns nomes publicitários da época são: Washington Olivetto, Roberto Duailibi, J. Roberto Penteado Filho, Eduardo Fisher, Alex Periscinoto, Nizan Guanaes, Renato Castelo Branco.

O retorno à democracia e o fim da censura rigorosa dão espaço a anúncios mais ousados. Novos produtos eram lançados. O feminismo mudou os padrões de comportamento da sociedade e a figura da mulher ganhou força. Algumas tendências atuais do século XXI começam a surgir nessa época: cuidado com o corpo e a forma física e a busca por uma vida saudável (GRACIOSO; PENTEADO, 2008).

Em 1986, Washington Olivetto entra para a história com o comercial "Primeiro Sutiâ" (para a Valisère) e no ano seguinte repete o feito com o comercial "Hitler" (para a Folha de São Paulo).

Em 1984, nas grandes cidades brasileiras, acontece o movimento pelas " $\mathrm{Di}$ retas já". Nasce, em 1988, uma nova constituição "mais liberal e moderna”. (MARCONDES, 2002, p. 52). As "Diretas já" sobrevivem e, em 1989, o Brasil vai às urnas e elege Fernando Collor de Mello.

Essa década é marcada pela volta à democracia. A esperança do povo brasileiro se renova com a expectativa de um país melhor e mais justo. A década de 90 também se inicia com homenagens e muitos prêmios: agência do ano, publicitário 
do ano, anúncio do ano, campanha do ano e profissional da década. O Brasil é considerado a terceira potência mundial em criação publicitária. Mas como ocorreu na década anterior, a propaganda teve também seus momentos dramáticos.

A partir de março de 1990, com a posse de Fernando Collor, o setor da prestação de serviços, entre outros, passa por dificuldades. Já no mês seguinte, as agências de propaganda começam a reduzir custos, cortando o quadro de pessoal. Isso acontece também nas emissoras de rádio e televisão. Imediatamente, a economia descontrola, reaparece o fantasma da inflação, provocando desemprego e levando muitas empresas à falência, frustrando todas as expectativas do povo com o novo governo (GRACIOSO; PENTEADO, 2008). O pior ainda estava por vir, os anunciantes do setor privado reduzem suas verbas a zero. Em 1991, o setor encolhe, sendo ainda pior que o ano anterior. O plano de Fernando Collor, que congelou novamente os preços, garante o péssimo desempenho do setor.

Em 1993, já com Itamar Franco na presidência, o setor retoma um ritmo mais próximo do normal. O grande feito do governo Itamar foi o lançamento do Plano Real, que lançou o Brasil nos trilhos da estabilidade econômica. Apesar das dificuldades econômicas nesse começo de década, a modernidade faz crescer o consumo, a qualidade dos produtos e surgir produtos importados no mercado brasileiro.

Fernando Henrique Cardoso assume a presidência em 1995 e "inicia-se uma nova e muito importante fase para a propaganda brasileira” (MARCONDES, 2002, p. 57). Para Gracioso e Penteado (2008), Fernando Henrique foi eleito pelo povo, pois transmitia confiabilidade, seriedade e porque defendia um programa de estabilização econômica. Fernando Henrique insere o Brasil no contexto mundial e moderniza as estruturas do país. O capital estrangeiro ganha mais participação em todos os setores da economia. A abertura de mercado provoca competitividade entre as empresas aqui instaladas e surge um consumidor cada vez mais exigente. O comércio varejista se moderniza e a tendência internacional de concentração de poucas empresas de grande porte chega ao Brasil.

A tecnologia ganha espaço importante, tanto na vida das pessoas quanto na comunicação. Essa é a década do início da World Wide (também conhecida como 
"Web" e "WWW") que viria a se tornar um fenômeno da comunicação mundial e da globalização. Fenômeno que desponta somente neste século, o XXI, pois até o final dos anos 90, as agências não tinham encontrado a maneira certa de "ganhar dinheiro" com a Internet. O computador e a Internet passam a ser peças "chaves", a desempenhar papéis importantes na propaganda brasileira e a explorar conceitos como: interatividade, globalização, realidade virtual, aproximação de fronteiras, segmentação, manipulação de imagens gráficas, personalização e quantidade infinita de informações. Esses são também os conceitos inseridos na propaganda. Não basta anunciar, tem que ser interativo, irreverente, personalizado, diferente e surpreender. $\mathrm{O}$ consumidor torna-se o grande foco da propaganda.

Francisco Gracioso, um dos autores do livro Propaganda Brasileira, define o papel da propaganda na sociedade como:

[...] a propaganda não reflete apenas os modos e os modismos, mas também os valores, atitudes e comportamento da sociedade. Até mesmo o humor das pessoas e o seu otimismo (ou pessimismo) em relação ao futuro são sutilmente reproduzidos pelos anúncios e comerciai (GRACIOSO; PENTEADO, 2008, p. 13).

\section{Metodologia da analise}

A análise dos anúncios deste estudo usará a abordagem proposta por Martine Joly, baseada na semiótica peirceana. A análise semiótica é uma teoria geral que nos permite ultrapassar as categorias funcionais da imagem.

Os signos são entidades importantes em semiótica. Para Peirce (2000) signo, ou representâmen, é aquilo que representa algo para alguém. Ele não é definido, pronto, ele é constituído no momento da percepção, no momento em que o homem o percebe e o identifica. Um signo dá origem a outro signo, ou seja, um pensamento acarreta outro. Esse signo mais desenvolvido é chamado de interpretante. Para Pierce (2000) o signo é fruto uma relação triárdiaca - Signo (Representâmen); Objeto; (Interpretante). Das várias classes de signos estruturadas por Pierce, será usada aqui a segunda tricotomia, que diz respeito à relação entre o referente/ob- 
jeto e o Representâmen ou a forma que usou para representar o objeto. Daí tem-se: ícone, índice e símbolo. O ícone é identificado por semelhança, equivalência e reconhecimento. O índice é a relação de causa e efeito. É um signo que se refere ao objeto que denota em virtude de ser realmente afetado por esse objeto. O símbolo é um signo que se refere ao objeto que denota em virtude de uma lei, normalmente uma associação de idéias gerais.

Martine Joly parte dessa compreensão funcional do signo e propõe um caminho para analisar anúncios publicitários. O modelo Joly de análise da imagem, inserido no livro Introdução à Análise da Imagem, mostra como a significação global de uma mensagem visual é construída pela interação de diferentes ferramentas, de tipos de signos distintos: plásticos, icônicos e linguísticos. Mostra também que a interpretação desses diferentes tipos de signos se relaciona com o saber cultural e sociocultural do receptor, de cuja mente é solicitado um trabalho de associações.

Assim, com o propósito de identificar a influência do contexto político-econômico nos anúncios impressos brasileiros nas décadas de 50 a 90, os anúncios escolhidos para cada década serão analisados a partir dessas duas perspectivas Semiótica de Peirce e Modelo Joly.

\subsection{Metodologia de escolha dos anúncios}

Os anúncios escolhidos para a análise pertencem a categorias diferentes de produtos, que vão desde sapatos até móveis de decoração. Essa escolha não foi por acaso. Era preciso mostrar o quanto o contexto dos fatos podia influenciar os diversos setores da sociedade. Essa escolha diversa visa mostrar o tamanho dessa influência.

As escolhas foram feitas após pesquisas de vários anúncios de todas as décadas. As pesquisas se deram em livros e em um acervo digital de uma das maiores revistas do país, que seguem respectivamente: Almanaque 100 de Propaganda, o livro Propaganda Brasileira e o acervo digital da Revista Veja. Foram selecionados três ou quatro anúncios, para cada década, que representavam a linha criativa do 
momento. Dentre esses anúncios selecionados, somente um, por década, foi escolhido para ser analisado conforme a semiótica de Pierce e o modelo Joly. Este reunia todas as características apresentadas pelos demais e representava em um único corpus a linha criativa da década.

\section{Análise dos anúncios}

As análises pressupõem os contextos já referidos anteriormente. As tabelas de apoio ás análises se encontram no Apêndice A.

\subsection{Análises dos anúncios da década de $\mathbf{5 0}$}

Esta análise é constituída de três anúncios da década de 50, sendo um do ano de 1950, o outro, do ano de 1954 e o último, do ano de 1955. A figura 01 apresenta o anúncio da geladeira Gelomatic 700, de 1955, publicado na revista $O$ Cruzeiro; A figura 02 apresenta o anúncio do liquidificador Walita, de 1954, publicado na revista $O$ Cruzeiro; A figura 03 apresenta o anúncio dos eletrodomésticos Walita, de 1950, publicado na revista Seleções.

\section{FIGURA 1 - Anúncio Anos 50}

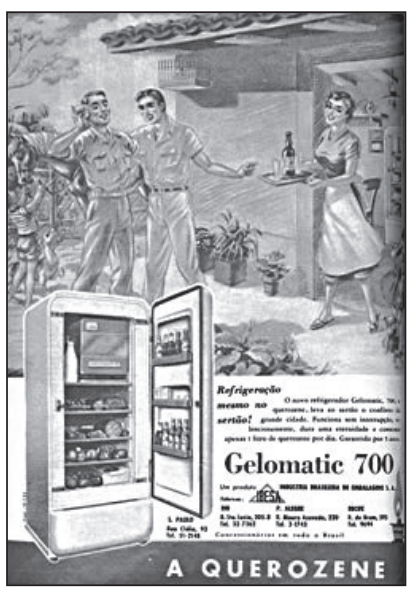

Fonte: 100 Anos de Propaganda. 


\section{FIGURA 2 - Anúncio anos 50}

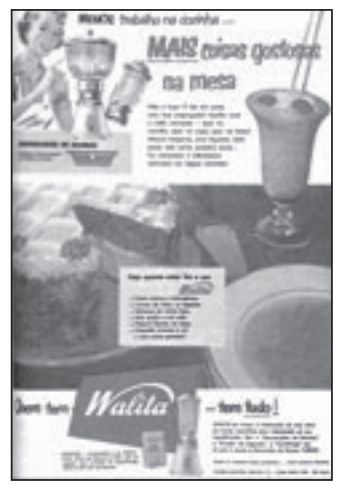

Fonte: 100 Anos de Propaganda.

\section{FIGURA 3 - Anúncio anos 50}

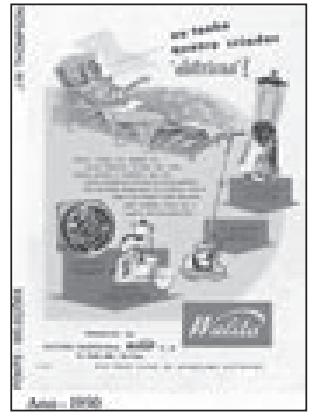

Fonte: Propaganda Brasileira.

Os anúncios analisados permeiam entre o Brasil essencialmente agrícola e as influências do american way of life (Estilo Americano de Vida). Os eletrodomésticos eram novidade no país. A ilustração e as rimas ainda dominavam os anúncios, influências ainda das primeiras décadas do século XX. Na maioria dos casos, os anúncios tinham grande quantidade de texto. É importante lembrar que o país tinha sua economia baseada na agricultura, da qual muitas famílias não supriam nem as necessidades básicas. Havia essa contradição entre o que era anunciado e para quem era anunciado, pois o modo de vida estrangeiro e a forma de se fazer comunicação eram mais evoluídas que as do Brasil. Os principais conceitos passados são: mulher do lar e submissa, facilidade, modernidade e tecnologia trazida pela american way of life. Tendo este último maior destaque. As cores eram diversas e 
predominavam os tons pasteis, transparecendo a tranquilidade e a previsibilidade da vida na época.

\subsection{Análise dos anúncios da década de 60}

Esta análise é constituída de quatro anúncios da década de 60 , sendo um do ano de 1966, um do ano de 1967 e dois do ano de 1968. A figura 04 apresenta o anúncio da gasolina do posto Esso, de 1968, publicado na revista Veja; A figura 05 apresenta o anúncio do avião Boing da Varig, de 1966, publicado na revista Realidade; A figura 06 apresenta o anúncio carro Fusca da Wolkswagem, de 1967, publicado na revista Manchete; A figura 07 apresenta o anúncio dos móveis da marca Securit, de 1968 ,publicado na revista Veja.

FIGURA 4 - Anúncio Anos 60

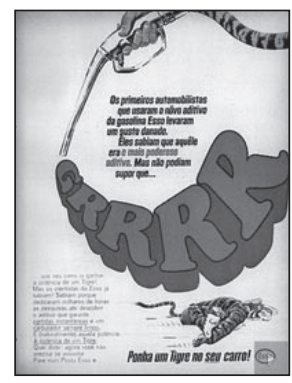

Fonte: http://www.veja.com.br/acervodigital

FIGURA 5 - Anúncio Anos 60

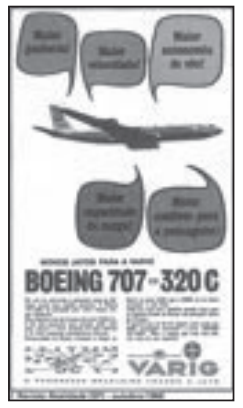

Fonte: 100 Anos de Propaganda 


\section{FIGURA 6 - Anúncio Anos 60}

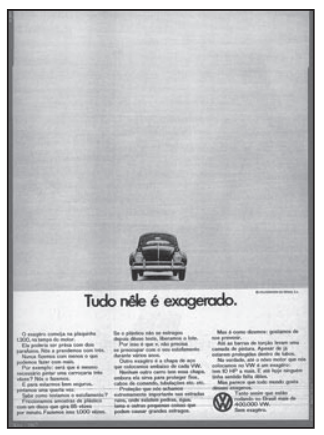

\section{FIGURA 7 - Anúncio Anos 60}

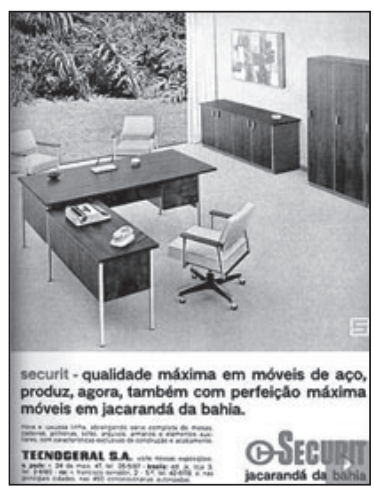

Fonte: Propaganda Brasileira http://www.veja.com.br/acervodigital

Todos os anúncios analisados apresentam um ponto em comum: o conceito de maioridade, de poder, de melhor, potência, superioridade, incontestabilidade e grandeza; Era o que o regime militar representava. As palavras "maior", “exagerado", "potência” e "máxima”, são as palavras proclamadas pelos anúncios. Assim como eram os conceitos proclamados pelo regime. Em três dos anúncios escolhidos (Gasolina ESSO, Móveis Securit e Boing da Varig) percebe-se a predominância das cores que iriam dominar os anúncios da década seguinte: o verde, amarelo e azul.

Entende-se que o regime militar começava a passar suas ideologias por meio dos anúncios publicitários. A presença das palavras que passam a ideia de poder está em todos os anúncios e marca a linha criativa da época. 


\subsection{Analise dos anúncios da década de 70}

Esta análise é constituída de quatro anúncios da década de 70, sendo dois do ano de 1972, um do ano de 1975 e o último do ano de 1978. A figura 08 apresenta o anúncio da marca de calçados Conga, de 1972, não tendo informação de qual mídia foi publicado. A figura 09 apresenta o anúncio do carro Veraneio, de 1972, publicado na revista Realidade. A figura 10 apresenta o anúncio da revista Quatro Rodas, de 1975, publicado na revista Homem. A figura 11 apresenta o anúncio dos maiôs Lycra, de 1978, publicado na revista Claudia.

FIGURA 8 - Anúncio Anos 70

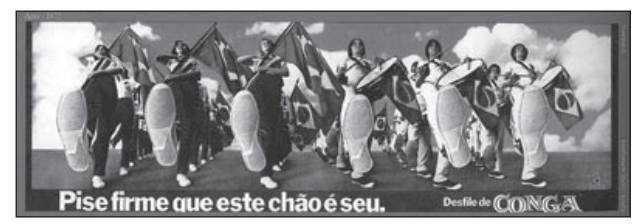

Fonte: Propaganda Brasileira

FIGURA 9 - Anúncio Anos 70

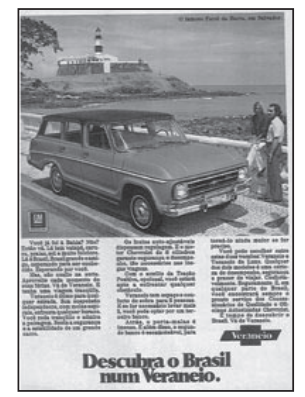

Fonte: Propaganda Brasileira

FIGURA 10 - Anúncio Anos 70

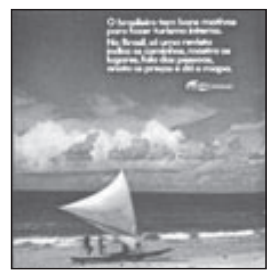

Fonte: 100 Anos de Propaganda 


\section{FIGURA 11 - Anúncio Anos 70}

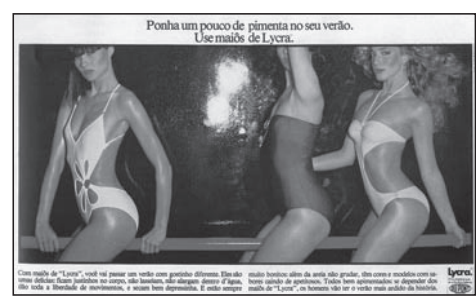

Fonte: Propaganda Brasileira

Nem sempre as peças desse período reproduziam as mensagens que o governo militar queria passar. Características marcantes nos três primeiros anúncios (Conga, Veraneio e Quatro Rodas) demonstram o que o governo queria passar à sociedade:

- Patriotismo;

- Equilíbrio;

- Uniformidade;

- Sincronismo; e

- Valorização do território nacional.

O governo investia também no turismo nacional. Percebe-se essa valorização nos anúncios da revista Quatro Rodas e do carro Veraneio - "O brasileiro tem bons motivos para fazer turismo interno"; "Descubra o Brasil num Veraneio. E juntamente com uma mensagem no âmbito subjetivo do anúncio da marca Conga passam a mensagem: "Descubra esse Brasil que é todo seu, Brasil de solo seguro e confiável”.

As cores verde, amarela, azul e branco estavam presentes em todos os anúncios analisados. Essas cores quando juntas passam uma única mensagem: patriotismo. As linhas regulares (retas ou diagonais) predominavam nos anúncios, representando a rigidez e imposição do regime. O Brasil era o foco principal de todos os anúncios. Era o Brasil patriota, solo seguro, que crescia, dos brasileiros que estavam satisfeitos em viver no país. O governo não se cansava de transmitir as palavras de ordem. De anúncio de carro a anúncio de sapato elas estavam direta ou indiretamente presentes.

O anúncio do ano de 1978, da marca Lycra, expressa na maioria dos detalhes o novo rumo que o país estava tomando: a abertura política rumo à democra- 
cia. O desequilíbrio da imagem é evidente; a presença de outra cor, se não o verde, amarelo, azul ou branco, a cor vermelha - que representa essa nova tendência, surgindo de forma lenta e gradual; a abertura na postura de duas das mulheres e a abertura nos maiôs delas representam o clima de abertura política que se instalava no Brasil; o texto do anúncio já apresenta "trocadilhos" e contexto mais permissivo; e a presença de linhas mais curvadas. Porém, a peça ainda contém elementos ligados ao regime militar, o qual só seria extinto na próxima década.

Em relação aos backgrounds, eram usados predominantemente dois padrões: fundo branco e/ou preto, apenas ressaltando a imagem e o texto; e fundo com alguma paisagem típica nacional, sejam paisagens naturais, sejam paisagens artificiais como monumentos arquitetônicos.

Diante do analisado como um todo, conclui-se que a relação entre o governo militar e as agências de propaganda era realmente íntima. Os produtos eram anunciados sob uma mensagem massiva e ideológica. As palavras de ordem eram implícitas ao discurso. Os anúncios reproduziam as mensagens que o governo militar queria passar..

\subsection{Análise dos anúncios da década de 80}

Esta análise é constituída de três anúncios da década de 80 , sendo um do ano de 1982, um do ano de 1987 e o último do ano de 1989. A figura 12 apresenta o anúncio dos lençóis da marca Artex, a figura 13 apresenta o anúncio do jeans da marca Ustop, de 1982, e a figura 14 apresenta o anúncio do sutiã da marca Valisère, de 1987. Não se tem informação de qual mídia foram publicados.

\section{FIGURA 12 - Anúncio Anos 80}

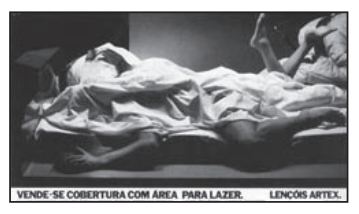

Fonte: Propaganda Brasileira 
FIGURA 13 - Anúncio Anos 80

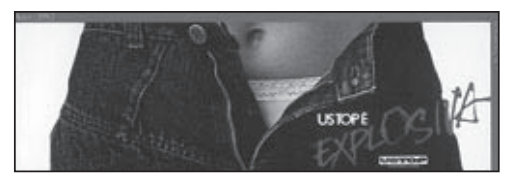

Fonte: Propaganda Brasileira

FIGURA 14 - Anúncio Anos 80

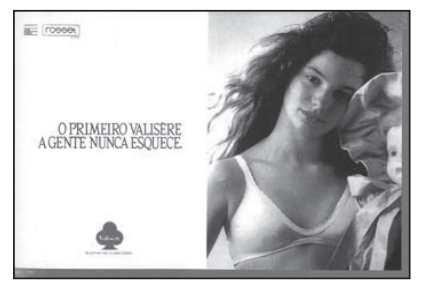

Fonte: Propaganda Brasileira

Os anúncios analisados representam bem o estilo criativo da época: ousadia na criação, produção simples e valorização da mulher. Como pode ser visto nas peças, o assunto sexo e sensualidade eram expostos, porém não de forma explícita. As abordagens carregavam um tom de sutileza como, por exemplo: no anúncio da Ustop a calcinha da mulher aparece parcialmente, porém é uma calcinha, de primeira vista, comportada e com detalhes de renda; também, o anúncio histórico e premiado da Valisère mostra um moçinha vestindo seu primeiro sutiã, porém, além dela carregar uma boneca nos braços, seu sutiã é simples e com a sutileza das rendas. A abertura da calça jeans no anúncio da Ustop e a posição de abertura corporal dos modelos no anúncio da Artex representam bem o clima de abertura política. Percebe-se o clima relaxado e de ousadia. Agora os publicitários estavam livres para soltarem a imaginação e a criatividade. Claro que dentro dos limites de moral e pudor.

Como esta década foi marcada por uma dificuldade econômica em todos os setores da sociedade, a propaganda também sentiu bem essa dificuldade. Como pode ser visto nesses anúncios analisados, as produções são simples e muito criativas no conceito. As cores predominantes nesses anúncios são neutras e marcam bem a presença da cor vermelha. Ressaltando que nenhuma das cores que predominavam nas últimas duas décadas - 60 e 70 -, o verde, amarelo e azul, aparecem nos anúncios. 
Após todas as análises, conclui-se que a dificuldade econômica que atingiu a propaganda afetou somente as produções, que ficaram mais simples, mas os publicitários não viram nisso empecilho para criar. E, diga-se de passagem, elas ficaram ainda mais criativas. Com imaginação e originalidade a propaganda se destaca no cenário internacional e é considerada uma das três mais criativas do mundo.

\subsection{Análise dos anúncios da década de 90}

Esta análise é constituída de três anúncios da década de 90, sendo todos do ano de 1996. A figura 15 apresenta o anúncio do carro Pajero da marca Mitsubishi; a figura 16 apresenta o anúncio do banco Bradesco, e a figura 17 apresenta o anúncio do iogurte da marca Danone. Todos foram publicados na revista Veja do ano de 1996.

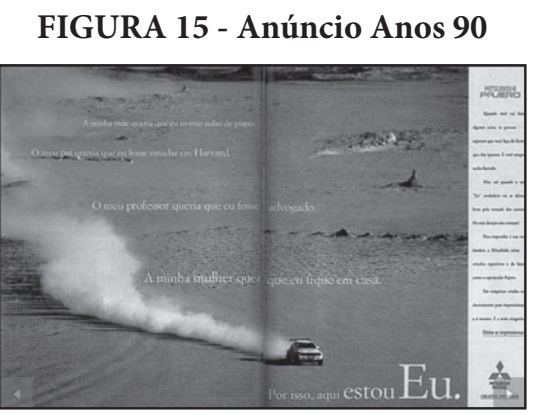

Fonte: http://www.veja.com.br/acervodigital

FIGURA 16 - Anúncio Anos 90

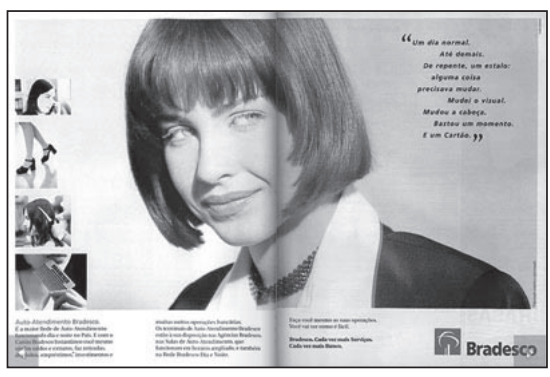

Fonte: http://www.veja.com.br/acervodigital 


\section{FIGURA 17 - Anúncio Anos 90}

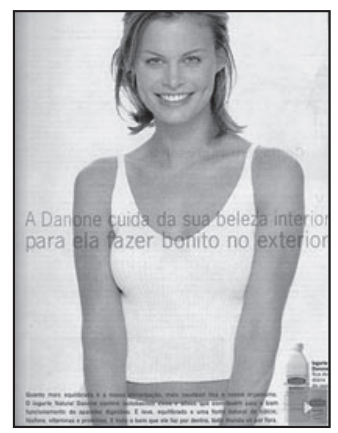

Fonte: http://www.veja.com.br/acervodigital

As peças analisadas refletem claramente dois momentos pelos quais o Brasil está passando: a "enfim" democracia, na qual o poder de tomar importantes decisões políticas (como eleger um presidente) está na mão do povo; e a abertura econômica, que trouxe a liberação de importações, a qual estimulou a competitividade interna e o aumento do capital estrangeiro na economia brasileira, modernizando o comércio varejista.

A democracia traz consigo a valorização do "Eu", a liberdade de escolhas, o poder sobre si e sobre seus sonhos. As peças da Mitsubishi e do Banco Bradesco transparecem essa característica. O "Eu" é o conceito principal das peças. "Eu faço minhas escolhas, eu posso consegui-las, por meus próprios meios". A predominância de linhas retas e regulares e as escolhas tipográficas (leves e clássicas) transmitem a estabilidade tão esperada pelo povo brasileiro.

Já o anúncio da Danone reflete o momento de liberalização das importações que trouxe produtos para o Brasil e colocou o país no âmbito mundial. O título do anúncio é que faz esse papel: "Danone cuida da sua beleza interior para ela fazer bonito no exterior". As formas predominantes também são linhas retas, passando a estabilidade já mencionada acima.

Conclui-se que os fatos político-econômicos não têm ligação direta com a mensagem passada nos anúncios, mas esses fatos desencadearam comportamentos e conceitos sociais que refletem na propaganda da década de 90. A única ligação di- 
reta entre fatos e escolhas no layout é a predominância das linhas retas e regulares transparecendo a calma e a estabilidade conquistada.

\section{Considerações finais}

A propaganda surgiu há séculos, e uma coisa que já está há tanto tempo entre nós não podia deixar de ter uma relação com o cotidiano, com os fatos político-econômicos e com o comportamento da sociedade. A propaganda é o espelho de tudo isso, ainda mais em se tratando de Brasil, onde a história sempre foi marcada pela política - que influenciava na economia e, consequentemente, na sociedade. E como a propaganda é espelho da sociedade, ela também era influenciada.

Neste estudo foi possível verificar até que ponto o contexto político-econômico da história do Brasil influenciou a nossa propaganda. Percebeu-se que a influência não se dá em um único setor e sim em toda a esfera da sociedade.

As décadas escolhidas compreendem um grande período histórico - 1950 a 1990 -, porém contemplam décadas que transformaram o Brasil, que marcaram o amadurecimento do país e de sua propaganda. Esse panorama deu ao estudo uma perspectiva que permite o melhor entendimento da sequência de acontecimentos ao longo da história.

Como a propaganda é feita por pessoas, pôde-se ver que ela transparece o que as pessoas estão experimentando e vivendo no momento. Ou seja, por mais que os publicitários tentem fazer escolhas estratégicas para passar a mensagem pretendida, eles estão inseridos em uma sociedade onde decisões e acontecimentos políticos e econômicos os afetam diretamente como pessoas. O que se quer dizer é que muitas das escolhas das propagandas impressas não foram propositais e sim porque se passava por um momento propício para aquelas escolhas.

A relação íntima entre governo e agências de publicidade, que a priori se deu somente no período da década de 70, mostrou-se íntima também nas outras décadas analisadas. Claro que nas décadas de 60 e 70 essa relação era mais forte e 
ideológica. Porém, nas outras décadas, os acontecimentos políticos e econômicos tinham consequências diretas no comportamento e nos hábitos da população, o que transparecia nos anúncios. Indiretamente e sutilmente, as decisões do governo influenciavam as propagandas. É importante ressaltar que a década de 50 é peculiar. Suas influências são ainda de anos mais distantes e o Brasil começa a se transformar nesse momento, o que só vai se refletir mais tarde.

Este estudo teve como objetivo mostrar a evolução da publicidade brasileira e como e quanto o contexto político-econômico da história do Brasil teve influência nessa evolução. A política e a economia são e foram importantes para a história não só da propaganda, como principalmente do Brasil. A propaganda não deixou, e espera-se não deixar, de evocar reflexões históricas, políticas, econômicas e também estéticas e culturais.

\section{The influence of political, economic printed in advertising of brazilian 50's to 90's: a semiotic}

\section{Abstract}

This study aims to identify the influence of political and economic context in print ads in Brazil 50's years to 90's. For this analysis were made three or four ads each decade belonging to different segments of the market. Report a history of synchronous and advertising of Brazilian history from the 50's to the late twentieth century, outlining the main events of politics, economics and propaganda. Presented in a next step, the methodology that was based analysis such as semiotics from the "model" Martine Joly. It is hoped that this study reveals the importance of political and economic context in the brazilian advertising.

Keywords: Advertising -Brazil. History-Brazil. Semiotics. 


\section{Referências}

BRASIL ESCOLA. Histórico João Goulart. Disponível em: <http://www.brasilescola. com/historiab/joao-goulart.htm>. Acesso em: 22 set. 2009. 11h02min.

BRASIL ESCOLA. Histórico Castelo Branco. Disponível em: <http://www. brasilescola.com/historiab/castelo-branco.htm>. Acesso em: 22 set. 2009. 11h20min.

BRASIL ESCOLA. Histórico General Médici. Disponível em: <http://www. brasilescola.com/historiab/general-medici.htm\#>. Acesso em: 5 out. 2009. 08h44min.

BRASIL ESCOLA. Histórico Ernesto Geisel. Disponível em: <http://www. brasilescola.com/historiab/ernesto-geisel.htm>. Acesso em: 16 out. 2009. 08h40min.

CASTELO BRANCO, Renato; MARTENSEN, Rodolfo; REIS, Fernando. História da propaganda no Brasil. São Paulo: T. A.Queiroz, 1990.

GRACIOSO, Francisco; PENTEADO, J. Roberto Whitaker. Propaganda Brasileira. 3. ed. São Paulo: M. I. Marketing, 2008.

HABERT, Nadine. A década de 70: apogeu e crise da ditadura militar brasileira. 3. ed. São Paulo: Ática, 1996.

JOLY, Martine. Introdução á análise da imagem. 10. ed. Tradução Marina Appenzeller. Campinas: Papirus, 2006.

MARCONDES, Pyr. Uma história da propaganda brasileira. Rio de Janeiro: Ediouro, 2002.

PEIRCE, Charles Sanders. Semiótica. Tradução José Teixeira Coelho Neto. 3. ed. São Paulo: Perspectiva, 2000.

RAMOS, Ricardo. Propaganda. 4. ed. São Paulo: Global, 1998.

RAMOS, Ricardo. Do reclame á comunicação: pequena história da propaganda no Brasil. 4. ed. São Paulo: Atual, 1987.

RODRIGUES, Marly. A década de 50: populismo e metas, desenvolvimentistas no Brasil. 4. ed. Ática: São Paulo, 2002.

100 anos de propaganda. São Paulo: Abril Cultual, 1980. 
VEJA. Acervo Digital. Disponível em: <http://www.veja.com.br/ acervodigital>. Acesso em: 20 set. 2009. 8h15min.

\section{APÊNDICE A - Tabelas de apoio à análise}

As análises foram compiladas nos quadros que seguem e a na identificação da tricotomia peirceana. Dentre os três ou quatro anúncios de cada década, um foi escolhido para ser analisado conforme a semiótica de Pierce e o modelo Joly, pois este reunia as características apresentadas pelos demais e melhor representava a linha criativa da década.

\section{Anúncio da Década de 1950}

Dos três anúncios em questão, foi escolhido o anúncio da geladeira Gelomatic 700 para ser analisado a partir das perspectivas da metodologia de análise.

\section{Mensagem Plástica}

\begin{tabular}{|c|c|}
\hline Significantes Plásticos & Significados \\
\hline Quadro & $\begin{array}{c}\text { Ausente: porém a imagem extingue } \\
\text { a possibilidade de complemento } \\
\text { imaginário. }\end{array}$ \\
\hline Enquadramento & $\begin{array}{c}\text { Horizontal e apertado: nitidez e } \\
\text { proximidade. }\end{array}$ \\
\hline Ponto de Vista & $\begin{array}{c}\text { Oblíquo e "à altura do homem e de } \\
\text { frente": destaque e visão natural. }\end{array}$ \\
\hline Composição & $\begin{array}{c}\text { A leitura é feita da esquerda para direita, } \\
\text { de cima para baixo. }\end{array}$ \\
\hline Formas & $\begin{array}{c}\text { Arredondadas e formas naturais: } \\
\text { sutileza e naturalidade. }\end{array}$ \\
\hline Dimensões & Grande e pequena. \\
\hline Cores & $\begin{array}{c}\text { Dominante tons pastéis: calma e } \\
\text { tranquilidade da época. }\end{array}$ \\
\hline Iluminação & Presente: em dois sentidos diferentes. \\
\hline Textura & Visual: relevo. \\
\hline
\end{tabular}


Mensagem Icônica

\begin{tabular}{|c|c|c|}
\hline Significados Icônicos & $\begin{array}{c}\text { Significados de } \\
\text { primeiro nível }\end{array}$ & $\begin{array}{c}\text { Conotações } \\
\text { de segundo nível }\end{array}$ \\
\hline Geladeira & Eletrodoméstico & Modernidade \\
\hline Mulher com bandeja & $\begin{array}{c}\text { Mulher servindo bebida } \\
\text { aos homens }\end{array}$ & Mulher submissa \\
\hline Avental & $\begin{array}{c}\text { Avental usado pela } \\
\text { mulher }\end{array}$ & $\begin{array}{c}\text { Mulher do lar, que não } \\
\text { trabalhava for a e vivia } \\
\text { para cuidar da casa. }\end{array}$ \\
\hline Garrafa & Cerveja sendo servida & Prazer masculino. \\
\hline Geladeira cheia & Fartura & $\begin{array}{c}\text { Armazenamento de } \\
\text { alimentos. }\end{array}$ \\
\hline Roupas sociais & $\begin{array}{c}\text { Roupas as quais os } \\
\text { homens usam }\end{array}$ & $\begin{array}{c}\text { Diferenciação/ } \\
\text { Contradição }\end{array}$ \\
\hline Crianças & Filhos & Família ideal. \\
\hline Chama & $\begin{array}{c}\text { Chama provocada pelo } \\
\text { querosene }\end{array}$ & $\begin{array}{c}\text { Carência de energia } \\
\text { elétrica no país. }\end{array}$ \\
\hline
\end{tabular}

Percebem-se divergências entre o que a ilustração expõe e a realidade do país. Isso se dá pelas influências estrangeiras que se instalaram no país e nas agências de propaganda; o que causava dissonância entre o que era anunciado e para quem era anunciado.

O anúncio apresenta três ícones principais: a ilustração de uma mulher, dos dois homens e da geladeira. Mulher e um dos homens indicam ser um casal, pela existência de duas crianças na cena. A geladeira indica fartura e armazenamento, por estar cheia. A posição dos corpos dos homens e da mulher indica movimentos corporais. Os elementos do cenário indicam que o local é o sertão. A mulher simboliza lar, feminilidade e submissão ao homem. A mulher juntamente com um dos homens e as crianças simbolizam família. A geladeira simboliza modernidade e tecnologia. As cores pastéis do anúncio simbolizam tranquilidade e a vida pacata das pessoas da época.

\section{Anúncio da Década de 1960}

Dos quatro anúncios em questão, foi escolhido o anúncio da gasolina do posto Esso para ser analisado a partir das perspectivas da metodologia de análise. 
Mensagem Plástica

\begin{tabular}{|c|c|}
\hline Significantes Plásticos & Significados \\
\hline Quadro & $\begin{array}{c}\text { Presente e ausente: delimitação e } \\
\text { complementação imaginária. }\end{array}$ \\
\hline Enquadramento & Amplo e levemente aproximado. \\
\hline Ponto de Vista & Levemente oblíquo e natural. \\
\hline Composição & $\begin{array}{l}\text { A leitura é feita da esquerda para direita, } \\
\text { de cima para baixo. A imagem propõe a } \\
\text { leitura da direita para esquerda: extrema } \\
\text { direita, lado politico do regime. }\end{array}$ \\
\hline Formas & $\begin{array}{l}\text { Predominância de formas arredondadas } \\
\text { porém com }\end{array}$ \\
\hline Dimensões & Gresçande e pequena. \\
\hline Cores & Dominante fria. \\
\hline Iluminação & Ausente \\
\hline Textura & Visual \\
\hline
\end{tabular}

Mensagem Icônica

\begin{tabular}{|c|c|c|}
\hline Significados Icônicos & $\begin{array}{c}\text { Significados de } \\
\text { primeiro nível }\end{array}$ & $\begin{array}{c}\text { Conotações } \\
\text { de segundo nível }\end{array}$ \\
\hline Tigre & Animal felino & Força, imponência, poder \\
\hline Onomatopéia & $\begin{array}{c}\text { Som produzido pelo } \\
\text { tigre }\end{array}$ & $\begin{array}{c}\text { Poder, grandiosidade, } \\
\text { potência e grande } \\
\text { propagação. }\end{array}$ \\
\hline Mangueira e bico & Abastecimento & Fornecimento de poder \\
\hline Rastros & $\begin{array}{c}\text { Ratros de velocidade } \\
\text { deixados pelo tigre }\end{array}$ & Velocidade, rapidez. \\
\hline Cor verde & Militar & Hegemonia militar. \\
\hline
\end{tabular}

Percebe-se que as palavras de ordem e de poder já começam a se instalar no anúncio.

O anúncio apresenta dois ícones principais: o tigre e a mangueira com bico de colocar gasolina. A mangueira, em que passa a gasolina, indica ser o rabo de um tigre, pela sua cor e detalhamento. O tigre indica movimento devido ao posicionamento da sua estrutura corporal e os rastros que ele deixa para trás. A onomatopéia indica grandiosidade e amplitude. O tigre simboliza força, poder e velocidade. As 
cores frias já fazem simbolismo ao regime militar e a única cor quente simboliza potência.

\section{Anúncio da Década de 1970}

Dos quatro anúncios em questão, foi escolhido o anúncio da marca de calçados Conga para ser analisado a partir das perspectivas da metodologia de análise.

\begin{tabular}{|c|c|}
\hline \multicolumn{2}{|c|}{ Mensagem Plástica } \\
\hline Significantes Plásticos & Significados \\
\hline Quadro & $\begin{array}{l}\text { Presente e ausente: delimitação e } \\
\text { crescimento sem limites. }\end{array}$ \\
\hline Enquadramento & $\begin{array}{l}\text { Horizontal e apertado: nitidez e } \\
\text { proximidade. }\end{array}$ \\
\hline Ponto de Vista & $\begin{array}{l}\text { Oblíquo e de baixo para cima: } \\
\text { proximidade e destaque. }\end{array}$ \\
\hline Composição & $\begin{array}{l}\text { A leitura é feita da esquerda para direita } \\
\text { de cima para baixo. Sofrendo quebras no } \\
\text { movimento de leitura. }\end{array}$ \\
\hline Formas & $\begin{array}{l}\text { Linhas e formas geométricas: dureza e } \\
\text { precisão. }\end{array}$ \\
\hline Dimensões & Destaque para a dimensão grande. \\
\hline Cores & Dominante fria. \\
\hline Iluminação & $\begin{array}{l}\text { Presente: lateral, da esquerda para } \\
\text { direita. }\end{array}$ \\
\hline Textura & Ausente \\
\hline
\end{tabular}

Mensagem Icônica

\begin{tabular}{|c|c|c|}
\hline Significados Icônicos & $\begin{array}{c}\text { Significados de } \\
\text { primeiro nível }\end{array}$ & $\begin{array}{c}\text { Conotações } \\
\text { de segundo nível }\end{array}$ \\
\hline Calças e blusas & $\begin{array}{c}\text { Uniformes usados por } \\
\text { rapazes e moças }\end{array}$ & $\begin{array}{c}\text { Uniformidade, todos } \\
\text { agindo da mesma forma e } \\
\text { com a mesma postura. }\end{array}$ \\
\hline Bandeira & Bandeira do Brasil & Patriotismo \\
\hline Faixa verde e amarela & Apoio de bandeira & Postura e respeito \\
\hline
\end{tabular}




\begin{tabular}{|c|c|c|}
\hline Significados Icônicos & $\begin{array}{c}\text { Significados de } \\
\text { primeiro nível }\end{array}$ & $\begin{array}{c}\text { Conotações } \\
\text { de segundo nível }\end{array}$ \\
\hline Fileiras & $\begin{array}{l}\text { Rapazes e moças } \\
\text { enfileirados }\end{array}$ & $\begin{array}{c}\text { Todos indo para uma } \\
\text { mesma direção, tomando } \\
\text { uma única atitude. } \\
\text { Equilíbrio. }\end{array}$ \\
\hline Mapa do Brasil & $\begin{array}{c}\text { Mapa do Brasil } \\
\text { estampado na blusa } \\
\text { sobre o peito esquerdo }\end{array}$ & Patriotismo \\
\hline Solado do tênis & $\begin{array}{c}\text { Solado do tênis, produto } \\
\text { anunciante }\end{array}$ & $\begin{array}{l}\text { Solo seguro, o Brasil é } \\
\text { seguro. }\end{array}$ \\
\hline Rapazes e moças & $\begin{array}{l}\text { Rapazes e moças que } \\
\text { marcham enfileirados }\end{array}$ & População \\
\hline Perna direita esticada & $\begin{array}{l}\text { Todos marcham com a } \\
\text { perna direita esticada }\end{array}$ & $\begin{array}{c}\text { Extrema direita, lado } \\
\text { político do regime militar. }\end{array}$ \\
\hline $\begin{array}{l}\text { Boa fisionomia de } \\
\text { rapazes e moças }\end{array}$ & $\begin{array}{c}\text { Rapazes e moças } \\
\text { confiantes e convictos }\end{array}$ & $\begin{array}{l}\text { Todos estão satisfeitos } \\
\text { com a situação de regime } \\
\text { do Brasil. }\end{array}$ \\
\hline Tambor & Instrumento & $\begin{array}{l}\text { Instrumento que ecoa } \\
\text { poder. }\end{array}$ \\
\hline Rapazes & $\begin{array}{l}\text { Rapazes posicionados à } \\
\text { direita }\end{array}$ & $\begin{array}{l}\text { Os homens que executam, } \\
\text { direita que executa. }\end{array}$ \\
\hline Moças & $\begin{array}{c}\text { Moças posicionadas à } \\
\text { esquerda }\end{array}$ & $\begin{array}{c}\text { Mulheres ainda não } \\
\text { tinham lugar respeitado } \\
\text { na sociedade. }\end{array}$ \\
\hline
\end{tabular}

Percebe-se a mensagem massiva e ideológica passada pelo governo. Nessa década, elas são passadas, praticamente, de forma direta. O que se queria dizer era rigor, imponência e patriotismo.

O anúncio apresenta quatro ícones principais: moças, rapazes, bandeiras do Brasil e tambores. A posição corporal dos modelos indica postura e rigidez. A posição das pernas indica movimento, como se estivessem andando para frente. Os rapazes indicam estar tocando os tambores pela posição de seus braços. As bandeiras do Brasil, assim como as cores predominantes no anúncio, simbolizam patriotismo, as fileiras de homens e mulheres simbolizam equilíbrio e homogeneidade, os tambores simbolizam poder que ecoa. 


\section{Anúncio da Década de 1980}

Dos três anúncios em questão, foi escolhido o anúncio dos lençóis da marca Artex para ser analisado a partir das perspectivas da metodologia de análise.

Mensagem Plástica

\begin{tabular}{|c|c|}
\hline Significantes Plásticos & Significados \\
\hline Quadro & $\begin{array}{c}\text { Principalmente ausente: porém a } \\
\text { imagem extingue a possibilidade de } \\
\text { complemento imaginário. }\end{array}$ \\
\hline Enquadramento & $\begin{array}{c}\text { Horizontal - apertado: proximidade. } \\
\text { "À altura do homem e de frente" com } \\
\text { impressão de proximidade. }\end{array}$ \\
\hline Ponto de Vista & $\begin{array}{c}\text { A leitura é feita da esquerda para direita, } \\
\text { de cima para baixo. }\end{array}$ \\
\hline Composição & $\begin{array}{c}\text { Predominância de linhas retas, } \\
\text { diagonais e linhas irregulares: } \\
\text { estabilidade e ousadia de falar em sexo. }\end{array}$ \\
\hline Formas & Pequena. \\
\hline Dimensões & Dominante neutras. \\
\hline Cores & $\begin{array}{c}\text { Presente: da esquerda para direita, de } \\
\text { cima para baixo. }\end{array}$ \\
\hline Iluminação & Visual: relevo. \\
\hline Textura & \begin{tabular}{c} 
Ponala \\
\hline
\end{tabular} \\
\hline
\end{tabular}

Mensagem Icônica

\begin{tabular}{|c|c|c|}
\hline Significados Icônicos & $\begin{array}{c}\text { Significados de } \\
\text { primeiro nível }\end{array}$ & $\begin{array}{c}\text { Conotações } \\
\text { de segundo nível }\end{array}$ \\
\hline Colchão & Cama & Descanso e lazer \\
\hline Casal & Relação & Amor, sexo \\
\hline Lençol & $\begin{array}{c}\text { Lençol remexido que o } \\
\text { casal usa para se cobrir }\end{array}$ & $\begin{array}{c}\text { "Diversão embaixo do } \\
\text { lençol”, lazer. }\end{array}$ \\
\hline Posição do casal & Descanso & Curtição dos lençóis. \\
\hline Lençol & $\begin{array}{c}\text { Coberta usada na hora } \\
\text { de dormir }\end{array}$ & $\begin{array}{c}\text { Cobertura } \\
\text { Pernas da mulher }\end{array}$ \\
\hline $\begin{array}{c}\text { Pernas abertas e } \\
\text { inclinadas cada um pranto e } \\
\text { um lado formando um } \\
\text { "V”. }\end{array}$ & $\begin{array}{c}\text { tranquilidade, levando } \\
\text { ao conceito de abertura } \\
\text { política. }\end{array}$ \\
\hline
\end{tabular}


Percebe-se o clima relaxado e de ousadia. Agora os publicitários estavam livres para soltarem a imaginação e a criatividade. Claro que dentro dos limites de moral e pudor.

$\mathrm{O}$ anúncio apresenta quatro ícones principais: homem, mulher, cama e lençol. Homem e mulher indicam ter se movimentado na cama, devido ao estado do lençol. O lençol indica ter sido remexido e amassado, devido às suas linhas irregulares. Homem e mulher indicam estar descansando na cama, devido às suas posições. Homem e mulher em cima da cama simbolizam casal/relação, a cama simboliza descanso/relaxamento e o lençol remexido em cima do casal simboliza, no caso do contexto do anúncio, diversão na cama.

\section{Anúncio da Década de 1990}

Dos três anúncios em questão, foi escolhido o anúncio do carro Pajero da marca Mitsubishi para ser analisado a partir das perspectivas da metodologia de análise.

\section{Mensagem Plástica}

\begin{tabular}{|c|c|}
\hline Significantes Plásticos & Significados \\
\hline Quadro & $\begin{array}{c}\text { Principalmente ausente: porém a imagem } \\
\text { extingue a possibilidade de complemento } \\
\text { imaginário. }\end{array}$ \\
\hline Enquadramento & Horizontal - Amplo: liberdade. \\
\hline Ponto de Vista & $\begin{array}{c}\text { De cima para baixo aproximando-se da } \\
\text { visão natural: domínio, controle. }\end{array}$ \\
\hline Composição & $\begin{array}{c}\text { A leitura é feita da esquerda para direita, de } \\
\text { cima para baixo. }\end{array}$ \\
\hline Formas & $\begin{array}{c}\text { Predominância de linhas retas: estabilidade. } \\
\text { Normais. }\end{array}$ \\
\hline Dimensões & $\begin{array}{c}\text { Uma neutra: calma, equilíbrio; e uma } \\
\text { quente: positivismo, futuro postivo. }\end{array}$ \\
\hline Cores & Presente: da direita para esquerda, lateral. \\
\hline Iluminação & Visual: terra e fumaça. \\
\hline Textura &
\end{tabular}


Mensagem Icônica

\begin{tabular}{|c|c|c|}
\hline Significados Icônicos & $\begin{array}{c}\text { Significados de } \\
\text { primeiro nível }\end{array}$ & $\begin{array}{c}\text { Conotações } \\
\text { de segundo nível }\end{array}$ \\
\hline Carro & Transporte & $\begin{array}{c}\text { Aventura, liberdade, lazer, } \\
\text { poder. }\end{array}$ \\
\hline Paisagem do deserto & Aridez & Liberdade e transparência \\
\hline Rastro & $\begin{array}{c}\text { Poeira produzida quando } \\
\text { o carro passa }\end{array}$ & $\begin{array}{c}\text { "O que ficou pra trás é } \\
\text { poeira." }\end{array}$ \\
\hline Marca & Mitsubishi & $\begin{array}{c}\text { Liberalização das } \\
\text { importações, trazendo } \\
\text { produtos importados ao } \\
\text { país. Modernização. }\end{array}$ \\
\hline
\end{tabular}

Percebe-se claramente a volta à calma e à estabilidade. A globalização e a modernidade também ficam evidentes na marca do produto anunciado.

$\mathrm{O}$ anúncio apresenta um ícone principal: o carro. $\mathrm{O}$ carro indica estar em movimento pela poeira de areia que ele deixa para trás. A paisagem indica ser uma região de deserto. O carro simboliza rapidez, independência, poder e modernidade; a paisagem do deserto simboliza estabilidade e transparência; a cor branda simboliza também estabilidade e a cor avermelhada da terra significa um futuro promissor. 
